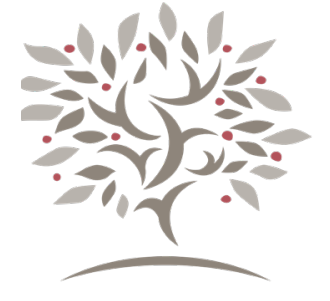

\title{
Transitioning from Early to Mid-Career as an Asian American Scholar of Religion
}

\author{
Tracy Sayuki Tiemeier \\ Loyola Marymount University
}

\begin{abstract}
A B S T R A C T
This article explores the post-tenure challenges and opportunities for Asian American scholars of religion. Although the pressure of service can be a burden on mid-level faculty, service can offer a fulfilling way to integrate one's scholarly work and one's commitment to Asian American communities. Moreover, even as excellence in teaching often is not given much (if any) weight in promotion to full professor, it can be mutually illuminative to experiment with teaching at the same time as one is also reassessing one's field and place within it. Indeed, the mid-career offers a unique standpoint from which one can bring teaching and research together in a synergistic way. Revised approaches to courses in comparative theology and Hinduism both enhanced the author's scholarship as well as allowed her to better serve her students. Integrating teaching, scholarship, and advocacy can be deeply productive for Asian American scholars of religion after tenure.
\end{abstract}

\section{KEYWORDS}

Asian American religious studies, comparative theology, teaching post-tenure

The relief that I felt after getting tenure was short-lived. I had the unsettling feeling of "Now what?" The freedom to pursue research, teaching, and service post-tenure was an incredible privilege, but the sense of responsibility was overwhelming. No longer did I have to worry about numbers of publications, course evaluations, or whether my scholarly work would fit narrow guild definitions of "scholarship"; instead, I could pursue my work as a teacherscholar-activist without fear. But what exactly should that work entail? What did it mean for me to develop my research and teaching beyond the limits of my field? And how would that prepare me for promotion to full professor?

Indeed, the transition to mid-career can be characterized by dueling poles of freedom and pressure. On the one hand, there is freedom to develop one's research agenda, to revamp old courses or teach new ones, to take on more leadership opportunities. On the other hand, whatever protections may be in place for junior faculty dissolve post-tenure. Increased service expectations-especially as faculty of color are encouraged to take on leadership positions-and the work of getting new research projects launched mean a crunch on time that all too often inhibits innovation in the classroom and a healthy balance of research and teaching, much less a balance of work and life. 


\section{Service, Administration, and Asian American Advocacy}

The post-tenure slump is, of course, a well-documented phenomenon (Mathews 2014). But it seems to me that there is one facet of this phenomenon that is felt deeply by Asian American scholars, as well as by other faculty of color: responsibility to a community within and beyond one's institution or academic guild. Such a commitment adds a great burden to the midcareer Asian American scholar; it also offers wonderful opportunities for personal and professional fulfillment.

I teach at Loyola Marymount University (LMU) in Los Angeles, CA. It is a Catholic university sponsored by the Society of Jesus (SJ), the Religious of the Sacred Heart of Mary (RSHM), and the Sisters of St. Joseph of Orange (CSJ-Orange). These partnering communities share an evangelical desire to know, love, and share God, but their missions and spiritualities impact the curriculum of LMU in distinctive ways. The Jesuit quest to "find God in all things" attends to formation of the whole person in "an education that transforms" (self and others); the CSJ charism of unity, extending the Ignation or Jesuit vision, emphasizes an education that brings about the reconciliation of all persons; and the Marymount mission "that all may have life" focuses on an education that addresses structural questions of justice. LMU's institutional hybridity holds in productive tension personal formation, unity, and structural justice. Such a holistic, integrative, and structural approach to education means that faculty are encouraged to hold teaching, research, and service together. Generally following a 40-40-20 model for our evaluation (40 percent teaching, 40 percent research, 20 percent service-though, really, service is upheld as much as teaching and research), LMU strives to cultivate teacher-scholars. Missional interests in engagement with society and work for justice mean that teaching and research engagement with Los Angeles and the world are highly valued.

This integrative approach to teaching, research, and service was quite empowering to me as I moved through the process of tenure and beyond. I found colleagues and administrators who valued my teaching as much as my research, and who valued my public engagement and service as a positive extension of my scholarly life. This allowed me to get to know Japanese American Los Angeles at a number of levels and made my early career as academically insightful as it was personally fulfilling. Even so, and especially post-tenure, I have found that the Ignatian value of magis (more) at LMU sometimes comes at the cost of cura personalis (care of the person). The push to teach, and research, and serve; the desire to do and be more; the pressure to be available constantly for service to department, college, university, academy, and wider world: all of this can be exhausting and unsustainable. Mid-level faculty are in transition and working to resituate themselves and their work, even as they are gearing up for promotion. And while leadership in service is important at the associate level, it can have an adverse effect on teaching and research.

Although the pressure of service can be a burden on mid-level faculty, it can also offer a fulfilling way to integrate one's scholarly work. An LMU Faculty Service Assessment Survey, for example, found that while White women and associate professors had generally negative views of service (in its assignment, evaluation, and reward), faculty from underrepresented racial and ethnic groups actually had more positive perceptions of faculty service (Barnhardt 2017). This was particularly the case when the service was seen to complement their scholarship or had to do with something they cared about. While there is no analysis of why this may be the case, the survey findings are suggestive of the extent to which service can be a positive expression of scholarly life for faculty of color.

This certainly fits with my own sense of service post-tenure. Because I had the security of tenure, I now felt the freedom to decline any number of committee nominations and invitations to speak or work on issues that were not central to my interests. Prior to tenure, I felt like I had to say yes to everything, both because I wanted to have a robust tenure portfolio but also because I didn't feel like I could tell more senior faculty, scholars, and administrators no. After tenure, I felt less vulnerable. I felt I could tell more senior colleagues no. At the same time, I was able to take leadership positions and accept service opportunities at local, university, and academic levels that fit with my explicit commitment to women of color and Asian and Asian American interreligious communities.

The question of higher administrative and other leadership opportunities can be a bit more difficult to navigate. To what extent is it important for Asian American scholars and other scholars of color at mid-career to move into these posts? And how might the move into administration delay (or even derail) the step to full professor? I've been lucky enough to have had two Asian American associate deans at LMU, both of whom were mid-career and made a great impact on me. Even so,

$1042021 ; 2: 1$ 103-108 The Wabash Center Journal on Teaching

This work is licensed under a Creative Commons Attribution-NonCommercial 4.0 International License 
the years spent in administration cannot come without cost to person, research, and teaching. One must therefore weigh a number of competing goods: personal interest in the position; the possibility in this position to mentor others and effect change for underrepresented persons and communities (versus the real possibility that one may end up being a tokenized voice with little power); a desire to explore the next step of a career, which may or may not include administration; and building one's portfolio for full professor.

\section{Balancing Research and Teaching at Mid-Career}

One of the great challenges for any scholar as they transition from early to mid-career is launching new research projects. For me, the freedom I felt post-tenure to rethink my research agenda and redefine my theological identity meant a wholesale questioning of my place in the field of comparative theology. As I had been trained, comparative theology was a deep, careful theological investigation of a religious tradition other than one's own, wherein the process of studying another tradition shed light on one's own. Careful boundaries, language study, and textual subtleties helped comparative theology be intellectually rigorous and ethically responsible to the traditions of study. But it often did not fit with my own Asian American Catholic experience, an experience that involved a good deal of ethnoreligious multiplicity, syncretism, and non-textual traditions. I wondered if my commitment to Asian and Asian American religious communities required me to shift away from the language of comparative theology. Of course, interreligious concerns would always be a part of my theological work; multireligiosity is fundamental to many Asian and Asian American contexts. But I wondered whether comparative theology was a helpful way to theologize in Asian and Asian American contexts when these contexts were so fluid and entangled.

Fortunately, the transition to mid-career is a perfect time to explore theory and methodology. At mid-career, all scholarsbut scholars of color especially-have the security they did not have before to push their fields theoretically and methodologically. As l've faced persistent questions about how gender, race, and ethnicity intersect with interreligious and comparative theological dynamics, I've been able to express those concerns and think constructively about them. In the process, l've connected with scholars within and beyond Asian, Asian American, and comparative theology. These connections have opened academic doors and initiated conversations that have brought me new academic life. The transition to mid-career can be a time of scholarly angst, but that angst can be productive if embraced.

With the intensity of getting research projects launched and a dramatic increase in service, it often seems like there is little time to revamp courses. In any case, teaching the same course semester after semester can lead to boredom and burnout in the classroom. But even as excellence in teaching is often not given much (if any) weight in promotion to full professor, it can be mutually illuminative to experiment with teaching at the same time as one is reassessing one's field and place within it. Indeed, mid-career offers a unique standpoint from which one can bring teaching and research together in a productive, synergistic way.

For example, pairing shifting research interests with small changes in the classroom (one unit, one source, one lecture, one class discussion, or one assignment at a time) each semester can have dramatic effects on a course experience. After several semesters of small changes, one will have redesigned a course in substantive ways. This experimentation with sources and approaches inevitably helps to clarify one's own developing research, theory, or method.

Take, for example, my lower-division core course in comparative theology. My initial approach to the course structure was to set up clear theological categories for comparison. Each category (for example, creation, death, ultimate reality, self) would consider scripture from each tradition (Hinduism and Christianity). While this theological and textual approach pushed students to not conflate traditions (they often came into the course assuming all religions are the same) as they had to look carefully for differences as much as for similarities, it did not allow for sufficient connection to the relationship between text and practice. Also, while many students came to a deeper appreciation of (comparative) theological inquiry and of Hinduism and Christianity, they did not seem to come to a transformational awareness of the living religious communities surrounding them. Finally, the strict boundaries and borders surrounding the categories I had constructed 
failed to connect with numerous students, many of whom grew up in interfaith, multireligious, or secular homes. Many of these students were of Asian descent, and I could identify with their mystification. They inspired me to look for ways to rethink my course, even as I had to be realistic about the limits of my time to completely revamp it all at once.

I started with stories, real and imagined. For example, I added a unit on Shusaku Endo's Deep River (1993). This novel about a group of Japanese tourists in India not only raised theological questions pertinent to the course, it allowed me to explore the history of India, the multireligiosity of Asia, and the complex negotiations of faith in people's lives. Although my research at the time wasn't directly engaging Endo, the unit provided space for me to start thinking about comparative theology in Asian contexts.

Other semesters, I expanded my units on gender and sexuality. Students read and researched Christian and Hindu women activists. They learned about women's rituals. Looking for comparative Christian examples for Hindu women's rituals pushed me to look into Latina Catholic popular ritual practices (Marian devotions, home altars, and so forth). While this wasn't a part of my research, I was deeply interested in the topic. Eventually, it did find its way to publication. My expanded unit on sexuality was also fruitful; from the research I conducted for the class, I was able to give a presentation on campus at an event after a troubling transphobic incident at LMU. In these ways, my course was improved at the same time as my research and activism were enriched.

A more radical possibility that can bring research and teaching together is to design new courses (where possible) that approach topics in innovative ways: community-based courses, team teaching, media studies courses, project-oriented learning, and so forth. Moving beyond the traditional classroom allows for engagement with religious communities in important ways that can prioritize lived religion and concrete religious persons. This pedagogical shift, in turn, informs religious and theological scholarship in the sources engaged and topics privileged.

One course I developed, “Pop Hinduism," incorporates contemplative pedagogy. The class examines the representation of Hinduism in American popular culture. Drawing on critical theory, we assess how American popular culture has received and reinterpreted Hindu theology in creative and sometimes problematic ways. One unit centers on yoga in film, television, and social media. In order to analyze the representation of yoga, we look at the development of modern yoga in the West and its introduction through a number of Indian gurus. Even as we read the Yoga Sutras, I don't want students to essentialize yoga as a static spiritual practice or to see the Yoga Sutras as the definitive source for yoga. So, I introduce them to a modern yoga tradition, Sivananda Yoga Vedanta, and have students practice in its lineage throughout the semester, both inside the classroom (every day at the beginning of class) and at the local Sivananda Yoga Vedanta Center (once or twice). Through this deep, more particular engagement, they are better equipped to think about yoga philosophy and practice. We meet with practitioners and learn from them; in the process, students see Hinduism and its many spiritual lineages as living traditions with powerful practices. They can no longer buy the stereotype of Hinduism they often see onscreen, or divorce yoga from its spiritual connection. For me, the process has helped attune my research to community concerns. For all of us, the contemplative classroom has made us more aware of the spiritual aspect of learning.

Finally, bringing Asian American and other students of color into research not only initiates students (and marginalized populations) into the creative process of research, it helps to bridge the teaching-research divide in a way that can help facilitate the transition to mid-career. This may involve faculty-mentored student research, joint research projects, hiring student research assistants, or more. In any of these scenarios, the challenge of meeting students where they are at and then moving with them through the research process can clarify what engages students (for the classroom) and what projects are important for the communities we aim to serve.

In the end, the most exciting parts of the transition to mid-career for me also tend to be the most difficult. Rejecting the boundaries surrounding Asian American teacher-researcher-activists does not mean that these areas will be integrated and balanced easily. Trying to do everything at once is a recipe for overwhelm and paralysis. Staying focused on a central concern (for me, privileging Asians and Asian Americans as well as women of color) and taking the mid-career one step at a time are essential.

106 2021; 2:1 103-108 The Wabash Center Journal on Teaching

This work is licensed under a Creative Commons Attribution-NonCommercial 4.0 International License 


\section{BIBLIOGRAPHY}

Barnhardt, C. L. 2017. LMU Faculty Service Assessment Survey: Trends and Findings. Iowa City, IA: University of Iowa Center for Research on Undergraduate Education.

Mathews, K. R. 2014. Perspectives on Midcareer Faculty and Advice for Supporting Them. Cambridge, MA: The Collaborative on Academic Careers in Higher Education. https://coache.gse.harvard.edu/files/gse-coache/files/ coache-perspectives-on.pdf? $m=1447625224$.

\section{ABOUT THE AUTHOR}

Tracy Sayuki Tiemeier is Associate Professor of Theological Studies at Loyola Marymount University in Los Angeles, CA. Her work focuses on comparative theology, Asian and Asian American theology, feminist theology, Hindu-Christian studies, and interreligious dialogue. 
